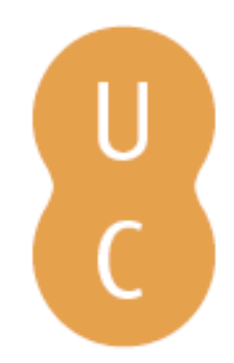

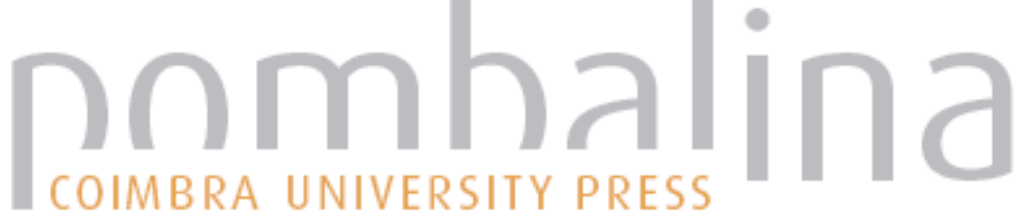

José Cardoso: o homem e o cineasta

Autor(es): Vieira, Sílvia

Publicado por: Imprensa da Universidade de Coimbra

URL

persistente: URI:http://hdl.handle.net/10316.2/43880

DOI: $\quad$ DOl:https://doi.org/10.14195/978-989-26-1395-6_9

Accessed : $\quad$ 26-Apr-2023 12:03:45

A navegação consulta e descarregamento dos títulos inseridos nas Bibliotecas Digitais UC Digitalis, UC Pombalina e UC Impactum, pressupõem a aceitação plena e sem reservas dos Termos e Condições de Uso destas Bibliotecas Digitais, disponíveis em https://digitalis.uc.pt/pt-pt/termos.

Conforme exposto nos referidos Termos e Condições de Uso, o descarregamento de títulos de acesso restrito requer uma licença válida de autorização devendo o utilizador aceder ao(s) documento(s) a partir de um endereço de IP da instituição detentora da supramencionada licença.

Ao utilizador é apenas permitido o descarregamento para uso pessoal, pelo que o emprego do(s) título(s) descarregado(s) para outro fim, designadamente comercial, carece de autorização do respetivo autor ou editor da obra.

Na medida em que todas as obras da UC Digitalis se encontram protegidas pelo Código do Direito de Autor e Direitos Conexos e demais legislação aplicável, toda a cópia, parcial ou total, deste documento, nos casos em que é legalmente admitida, deverá conter ou fazer-se acompanhar por este aviso.

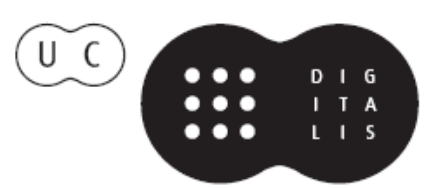



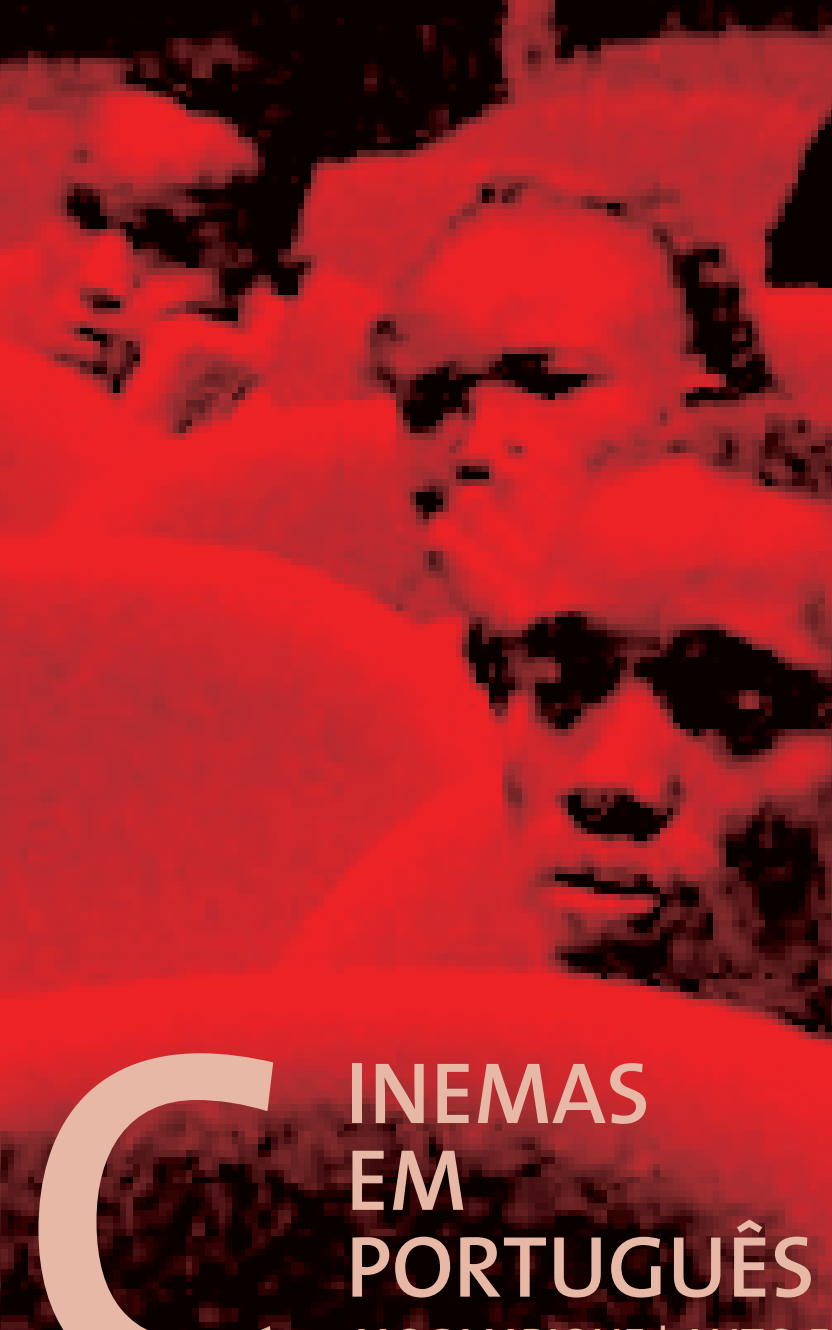

INEMAS

EM

PORTUGUÊS

MOÇAMBIQUE | AUTO E HETEROPERCEÇÕES

JORGE SEABRA

COORDENAÇÃO 


\title{
JOSÉ CARDOSO: O HOMEM E O CINEASTA
}

\author{
Sílvia Vieira \\ Universidade do Algarve \\ Centro de Investigação em Artes e Comunicação
}

Nós éramos os que sabiam que não sabiam e procuravam saber. E foi o que fizemos.

José Cardoso

José António Cardoso, nasceu em Figueira de Castelo Rodrigo, em Portugal, a 6 de Abril de 1930. Com apenas 8 anos foi viver para a cidade de Maputo em Moçambique, onde estudou e trabalhou na Farmácia Central até 1946, ano em que decide ir viver para a cidade da Beira. É precisamente aí que José Cardoso inicia a sua carreira no cinema. A sua aprendizagem faz-se em dois espaços de reflexão: o Grupo de Amadores de Cinema da Beira e o Cineclube da Beira.

Obedecendo à sua paixão pelo estudo da imagem em movimento participa no Grupo de Amadores de Cinema da Beira acompanhado por Carlos Alberto Lança, Francisco de Freitas, Luís Aboim, Augusto Peres e Alberto Silva entre outros, e lança-se aí no estudo dos segredos da manipulação dos sonhos, da teoria, da prática e das técnicas indispensáveis para se fazerem filmes (Cardoso, 2009, p. 13).

O Grupo de Amadores cria uma biblioteca com livros e revistas e assina um curso por correspondência produzido em Hollywood. Conforme José Cardoso "logo às primeiras lições que nos foram 
remetidas apercebemo-nos que tinham muito de propaganda do modo vivendi americano e pouco de ensinamentos sobre a teoria e técnica da produção de filmes" (Cardoso, 2009, p. 13). Em 1953, o grupo já conta com uma centena de membros. É dentro deste círculo, nomeadamente nas pessoas de João Santos e Álvaro Simões que nasce a ideia de formar um Cineclube e incluir nele uma secção de cinema de amadores, projeto ao qual se dedicam fervorosamente até à criação, em 1956, do Cineclube da Beira, o primeiro fundado em Moçambique, e do qual José Cardoso foi o sócio fundador número seis. Acompanham-no com a mesma paixão pelo cinema nomes tais como Vítor Rodrigues Patrocínio, Joaquim José Elias, Nunes Cordeiro, Noronha Marques, José Afonso, João Afonso dos Santos, Artur Crespo e Artur Costa entre outros. Organizam-se no Cineclube festivais de cinema amador, exposições regulares e "inúmeras iniciativas na divulgação do bom cinema e na educação cinematográfica dos seus associados, com debates e palestras sobre os filmes exibidos, os seus conteúdos humanos, sociais e políticos, os objetivos e a linguagem utilizada pelos seus realizadores (Cardoso, 2009, p. 13). Foram assim exibidos filmes tais como Abismos de Passíon (1953) de Luis Buñuel, Bellíssima (1952) de Luchino Visconti e O Couraçado Potemkine (1925) de Serguei Eisenstein. É neste ambiente cineclubista de constantes aprendizagens e experiências que José Cardoso realiza a sua primeira ficção - O Anúncio (1966) e ainda os filmes Raízes (1968) e Pesadelo (1969). Nestes filmes, a escolha do tema, o argumento, a direção de técnicos e atores, a montagem e a edição foram da sua autoria, com exceção de $O$ Anúncio em que a câmara e a fotografia foram da autoria de Gil Delgado. Em relação a este filme José Cardoso escreve, "fui muito criticado, pois naquela altura fiz um filme sobre a história de um branco desempregado quando havia tantos pretos empregados a passar fome. (...) Mas eu pretendo que os meus filmes sejam universais, que expliquem os problemas dos homens" (Vieira, 2010). $O$ Anúncio abre com a canção Vejam Bem, membro ativo do Cineclube 
da Beira, José Afonso (1929-1987), cantor e compositor cujas canções foram entoadas por tantos portugueses como símbolos de resistência ao salazarismo, era na época professor no Liceu da Beira, e tendo assistido à montagem do filme surpreendeu José Cardoso no dia seguinte com a composição Vejam Bem. O Anúncio recebeu vários prémios e distinções entre as quais o Prémio de Melhor Interpretação Masculina e da Melhor Mensagem Humana no Festival de Cinema Amador de Guimarães em 1967. José Cardoso orgulhava-se ainda das críticas positivas ao filme vindas da metrópole, em particular um texto escrito pelo crítico de cinema Fernando Gonçalves Lavrador, no número 291 da Revista Vértice de Dezembro de 1967, na qual afirma que o filme se deve apontar como exemplo a todos os amadores, não só pela sua beleza formal, mas também e sobretudo, pela riqueza temática, pela mensagem humana, pela verdade e simplicidade da situação dramática de um homem sem horizontes, perdido na indiferença de uma festa carnavalesca (Cardoso, 2009, p. 30). Em 1969, José Cardoso realiza Pesadelo, o seu filme mais crítico e polémico. No Festival de Cinema do Lobito foi apreendido pelas autoridades coloniais por ser considerado provocatório. José Cardoso escreve que pretendia denunciar os militarismos despóticos e prepotentes ao serviço das ideologias ditatoriais - no filme simbolizado pelas botas, e despertar as mentes para a necessidade de resistir lutando. E remata dizendo: "o incidente acontecido no Lobito, constitui para mim, o prémio maior que o Pesadelo alcançou (Cardoso, 2009, p. 34).

Em 1976, José Cardoso abandona o emprego na Farmácia Graça onde trabalhava há 32 anos, para aceitar o convite do então diretor do Instituto Nacional de Cinema (INC), Américo Soares, para abrir uma delegação na Beira. A sua prioridade foi mostrar filmes aos moçambicanos que nunca tinham visto imagens em movimento, o que faz com a sua equipa, ao criar uma unidade de cinema móvel que se deslocava para os lugares mais remotos da província. Trabalha neste projeto afincadamente durante dois anos. Em 1978, vai para Maputo 
na qualidade de quadro técnico do INC, participando da produção e edição dos jornais cinematográficos Kuxa Kanema. Realiza os documentários Que Venham (1981), Canta meu irmão... ajuda-me cantar (1982), Búzi, As Duas Margens de Um Rio (1983) e a Batalha Económica (1983), assim como os filmes de ficção O Papagaio (1982), Frutos da Nossa Colheita (1984) e 10 Passos para o Futuro (1985). É em 1986, que José Cardoso realiza a sua primeira longa-metragem de ficção $O$ Vento Sopra do Norte. O filme foi inteiramente financiado pelo INC, e nele trabalharam todos os técnicos do Instituto. Nesta ficção, José Cardoso reflete acerca dos últimos momentos da ocupação portuguesa. As cenas retratam a guerra de libertação de Moçambique, e a fuga generalizada dos colonos para a metrópole. Quando questionado sobre a influência que o INC teria tido sobre a sua decisão em tratar o tema da guerra colonial e do êxodo de colonos, José Cardoso em entrevista à autora respondeu "Não me senti condicionado. O tema marca uma época que vivi e que me marcou. $\mathrm{O}$ avanço da luta armada e a fuga precipitada dos colonos para Portugal e África do Sul, sem razão que o justificasse" (Vieira, 2010).

Em 1986, o Presidente da República de Moçambique Samora Machel, morre num misterioso acidente aéreo em território Sul Africano. Em 1989, a Frente de Libertação de Moçambique (FRELIMO) renuncia formalmente ao marxismo-leninismo, conduzindo o país às eleições multipartidárias. A Guerra Civil (1977-1992) e a crise económica que se instalam no país, enfraquecem o INC. Na cidade de Maputo, várias salas de cinema são desativadas, o cinema móvel não consegue fazer projeções nas províncias. $\mathrm{O}$ incêndio que deflagra nas instalações do instituto a 12 de fevereiro de 1991, mergulha-o num estado de letargia. Para José Cardoso, o incêndio foi simbólico da decadência da instituição (Vieira, Sílvia, 2010). Surgem neste contexto as primeiras produtoras privadas. José Cardoso toma a iniciativa e forma com os cineastas Camilo de Souza, Isabel Noronha, Leite de Vasconcelos, Paulo de Sousa, e o jornalista José Quatorze, a COOPIMAGEM. Realiza os 
documentários Mais Largo e Mais Fundo (1990), Os Sinaleiros (1992), O Nosso Ambiente (1998), e as ficções A Mosca do Vizinho, A Carta, e $O$ Madeireiro (2000). Depois destes três filmes de ficção sobre a temática do ambiente, desiludido com a política para o cinema em Moçambique, José Cardoso retira-se e dedica-se a escrever as suas memórias até à sua morte em 2013.

A paixão pelo cinema comandou a vida de José Cardoso. Homem de fortes convicções políticas, participou ativamente na divulgação e construção do cinema em Moçambique. Autodidata, cineasta amador afirmou-se ao longo dos anos como um dos mais importantes realizadores moçambicanos.

\section{Bibliografia}

Cardoso, José - O Cineclube da Beira. Dos anos 60 à Independência. Lisboa: Apenas, 2009.

\section{Entrevista}

Vieira, Ś́lvia - Maputo, Moçambique, 20 de Abril de 2010.

\section{Filmografia}

Vieira, Sílvia, Silva, Bruno. Assim estamos livres: cinema moçambicano 1975-2010. CIAC/Colateral, 16', cor, 2010. 